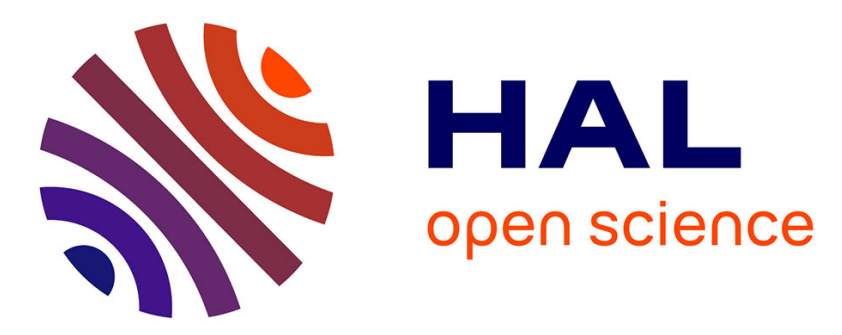

\title{
PHYSICAL PROPERTIES OF ALKALI METAL-AMMONIA (AMINE) SOLUTIONS STUDIED BY MAGNETIC RESONANCE METHODS
}

Y. Nakamura

\section{- To cite this version:}

Y. Nakamura. PHYSICAL PROPERTIES OF ALKALI METAL-AMMONIA (AMINE) SOLUTIONS STUDIED BY MAGNETIC RESONANCE METHODS. Journal de Physique IV Proceedings, 1991, 01 (C5), pp.C5-61-C5-70. 10.1051/jp4:1991507 . jpa-00250631

\section{HAL Id: jpa-00250631 https://hal.science/jpa-00250631}

Submitted on 1 Jan 1991

HAL is a multi-disciplinary open access archive for the deposit and dissemination of scientific research documents, whether they are published or not. The documents may come from teaching and research institutions in France or abroad, or from public or private research centers.
L'archive ouverte pluridisciplinaire HAL, est destinée au dépôt et à la diffusion de documents scientifiques de niveau recherche, publiés ou non, émanant des établissements d'enseignement et de recherche français ou étrangers, des laboratoires publics ou privés. 


\title{
PHYSICAL PROPEI'TIES OF ALKALI METAL-AMMONIA (AMINE) SOLUTIONS STUDIED BY MAGNETIC RESONANCE METHODS
}

\author{
Y. NAKAMURA \\ Department of Chemistry, Faculty of Science, Hokkaido University, Sapporo 060, Japan
}

\begin{abstract}
Characteristic features of the physical properties of metal-ammonia(amine) solutions are reviewed. The concentration fluctuations and the pairing of the excess electrons are considerable in the intermediate region of $\mathrm{Li}$ - and Na-ammonia solutions, where metal-nonmetal transition takes place. On the other hand, Li-methylamine solutions seem more homogeneous in the intermediate region, exhibiting similar electric properties to those of molten semiconductors.
\end{abstract}

\section{Introduction}

The most striking feature of metal-ammonia(amine) solutions(MAS) is that these are solutions of 'electrons' in insulating liquids. The physical properties of the solutions change drastically following the concentration of electrons. In dilute solutions the electrons are localized as solvated electrons, while in concentrated solutions they are delocalized, forming a Fermi gas. Many physical properties such as thermodynamical and dynamical properties have so far been investigated as a function of electron or metal concentration, temperature and pressure. In this review I would like to present some fundamental characteristics of these solutions, obtained mainly from magnetic resonance methods.

\section{Magnetic susceptibility and spin-pairing}

The first measurement of the magnetic susceptibility of MAS by the electron spin resonance(ESR) method has been reported by Hutchison and Pastor/1/ in the nonmetallic region of $\mathrm{Na}-\mathrm{NH}_{3}$ and $\mathrm{K}$ $\mathrm{NH}_{3}$. They used relatively low resonance frequencies, $5.5-8.2 \mathrm{MHz}$. Essig and Schindewolf/2/ have reported later susceptibility data for $\mathrm{Na}-\mathrm{NH}_{3}$, determined by ESR over a wide concentration range, covering from the nonmetallic to metallic regions. The susceptibility in the metallic region of $\mathrm{Na}-\mathrm{NH}_{3}$ and $\mathrm{Cs}-\mathrm{NH}_{3}$ has also been studied by Lelieur and Rigny/3/ from the static Gouy method. The electronic paramagnetic susceptibility was deduced from the observed susceptibility by subtracting the contributions from the metal ions and ammonia molecules on the basis of the Wiedemann mixing rule. The results of the electronic paramagnetic susceptibility for $\mathrm{Na}^{-\mathrm{NH}_{3}}$ and $\mathrm{K}-\mathrm{NH}_{3}$ are shown in Fig. 1. The results from the ESR and static measurements are in good agreement. Such a comparison has also been made by Harris and Lagowski/4/, using their ESR data in the nonmetallic region of $\mathrm{Na}-, \mathrm{K}-, \mathrm{Rb}$ - and $\mathrm{Cs}-\mathrm{NH}_{3}$. Like other electronic properties such as the electrical conductivity, the electron paramagnetic susceptibility is primarily independent of the sort of alkali metals. An exceptional behavior of large negative (diamagnetic) susceptibility below 2 MPM has been reported for $\mathrm{Li}-\mathrm{NH}_{3} / 5 /$.

The most important feature of the electronic susceptibility in metal-ammonia solutions is a strong reduction of the paramagnetism between 0.01-1 MPM, reflecting formation of diamagnetic species. The pairing of two solvated electrons with some cation involvement is considered. Ion pairs $\left(\mathrm{e}^{-} \mathrm{M}^{+} \mathrm{e}^{-}\right.$ 


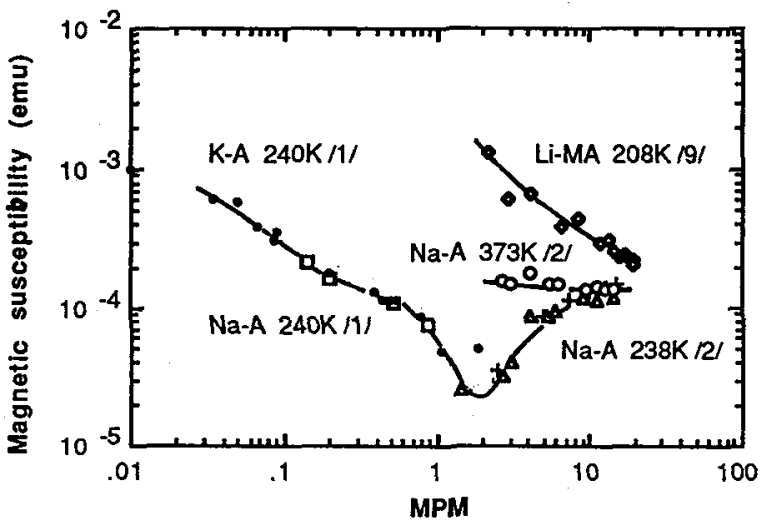

Fig. 1 Electron paramagnetic susceptibility of metal-ammonia(A) and methylamine(MA) solutions

) may be most probable diamagnetic entities/6,7/ in metal-ammonia solutions, while alkali metal anions $\mathrm{M}^{-}$are demonstrated in some amine or ether solutions/6,8/. In Fig. 1, we plot also the electronic susceptibility for $\mathrm{Li}-\mathrm{CH}_{3} \mathrm{NH}_{2}$ determined by the static method/9/. The curve shows no minimum, which suggests that the spin-pairing is less pronounced in $\mathrm{Li}-\mathrm{CH}_{3} \mathrm{NH}_{2}$. In this system the metal-nonmetal transition takes place around $15 \mathrm{MPM} / 10 /$. It should be noted, however, that the composition dependence of the magnetic susceptibility of $\mathrm{Na}-\mathrm{NH}_{3}$ at $373 \mathrm{~K} / 2$ / is similar to that of $\mathrm{Li}-\mathrm{CH}_{3} \mathrm{NH}_{2}$. This indicates that the diamagnetic species in metal-ammonia solutions dissociate at higher temperatures. The spin-paired species are much less stable in $\mathrm{CH}_{3} \mathrm{NH}_{2}$ even at low temperatures, probably due to the larger size of the solvent molecules.

It has been well established that the electrons in extremely dilute solutions are described as noninteracting free spins. It has been also well established that in the other extremity of concentrated solutions, dissolved electrons are existing just like as free electrons in normal liquid metals. The electronic paramagnetic susceptibility in the metallic region can be described by the Pauli paramagnetism with the diamagnetic contribution given by Landau formula. It is very interesting to see that in the intermediate region the spin-pairing reactions between the dissolved electrons proceed prior to the nonmetal to metal transition. The fundamental nature of the interaction between two solvated electrons to form spin-paired species is not yet clear.

The knowledge of the electron paramagnetic susceptibility is indispensable in the analysis of the Knight shift data. All the nuclei studied in MAS except ${ }^{1} \mathrm{H}$ show positive values for the Knight shift, reflecting the hyperfine interaction with the paramagnetic excess electrons. Negative shifts for ${ }^{1} \mathrm{H}$ have been interpreted by an indirect hyperfine coupling between the excess electrons on $\mathrm{N}$ and $\mathrm{H}$ via $\mathrm{N}-\mathrm{H}$ bonding/11/. Detailed investigation of the electronic contribution of the magnetic susceptibility will be needed in order to investigate the electronic state of MAS, in particular, in the intermediate region. For this purpose the method proposed by Schumacher and Slichter/12/ will be useful, in which the conduction electron spin resonance and the nuclear spin resonance are measured at the same frequencies. This is one of the reasons why we started a study with low-field ESR, which will be presented in a latter section.

Now, I would like to cite another interesting work concerning with the spin-pairing phenomena in metal-ammonia solutions. It has been reported occasionally that frozen metal-ammonia solutions show anomalously high electrical conductivity. For instance, Dmitrenko and Shchetkin/13/ have reported that freshly frozen $\mathrm{Na}-\mathrm{NH}_{3}$ with composition of 2.5-3.2 MPM showed a conductivity as high as $10^{7}-10^{8} \mathrm{~S} / \mathrm{cm}$ at $77 \mathrm{~K}$. The role of the spin-paired species or a Bose condensation of excess electrons has been suggested/14/. More recently, Arendt/15/ has reported that liquid metal-ammonia solutions with initial composition around 3 MPM showed anomalous electric properties during the decomposing process of the solutions. He claimed that the phenomena were transient. I think that these results are worth confirming in connection with the unusual behavior of electrons in the intermediate region of MAS. 


\section{Dielectric anomaly and MNM transition}

Edward and Sienko/16/ have demonstrated that the metal-nonmetal(MNM) transition in various impurity doped systems can be described universally by a particular scaled form of the Mott criterion

$$
\mathrm{n}_{\mathrm{c}}^{1 / 3} \mathrm{a}_{\mathrm{H}^{*}}=0.26 \pm 0.05
$$

where $n_{c}$ is the critical electron concentration and $a_{H} *$ is the effective Bohr radius for the localized electron state. The above expression is derived by the approach from the metallic state, taking account of the beakdown of screening of the ionic potential by the electron gas. On the other hand, Edwards and Sienko have also shown that the approach from the insulating state to the metalnonmetal transition based upon the Hertzfeld theory of polarization catastrophe/17/ is equally effective in the prediction of the metallic state of the chemical elements in the periodic table(18). In this approach the ionic potential, $V(r)=-e^{2} / \kappa * r$, in the nonmetallic region becomes zero, if the effective dielectric constant $K *$ becomes infinity at the critical concentration for metallization. The experimental detection of such polarization or dielectric catastrophe have been attempted in the vicinity of the metal-nonmetal transition region in single- and multicomponent systems/19/ .

The first measurements of the microwave dielectric constant of metal-ammonia solutions were made on $\mathrm{Na}-\mathrm{NH}_{3}$ at $10 \mathrm{GHz}$ by Mahaffey and Jerde/20\%. They reported that the real part of the dielectric constant, $\varepsilon^{\prime}$, increased sharply around 1 MPM and then changed their sign around 2 MPM, in accordance with the theory which predicts large negative values of $\varepsilon^{\prime}$ for metals. Similar behavior of the dielectric constant have been reported by Breitschwerdt and Radscheit for $\mathrm{Na}$ $\mathrm{NH}_{3} / 21 /$ and $\mathrm{Li}-\mathrm{NH}_{3} / 22 /$ at $6 \mathrm{GHz}$. Recently, Damay, Leclercq and Lelieur/23/ have determined the dielectric constant from the lineshape of the ESR spectra of $\mathrm{Li}-\mathrm{NH}_{3}$, base on their theoretical analysis of the spectral shape/24/. The precision of their dielectric constant data seems much better than that of classical microwave methods. Their results for $\varepsilon^{\prime} / 23 /$ are shown in Fig. 2, together with some of the previous data.

The dielectric anomaly is seen around 1.5 MPM and a metallic behavior is observed above 3 MPM. The anomaly of the dielectric constant is observed as a large maximum in the transition region instead of a real divergence, probably due to the large fluctuations of concentration approaching to the transition region. A real divergence of the dielectric constant has been observed in doped semiconductors such as Si:P at $0 \mathrm{~K}$, approaching to the critical concentration of the doped element from the insulator state/25/. In Hertsfeld's original theory of polarization catastrophe, the Clausius-Mossotti relation is used, in which the polarizability of molecules or atoms in the materials is considered to remain constant for all concentrations or densities. In metal-ammonia solutions the polarizability of the localized electrons is determined by the dielectric constant itself of the solutions. The self-constancy should be required in any computation based on this treatment.

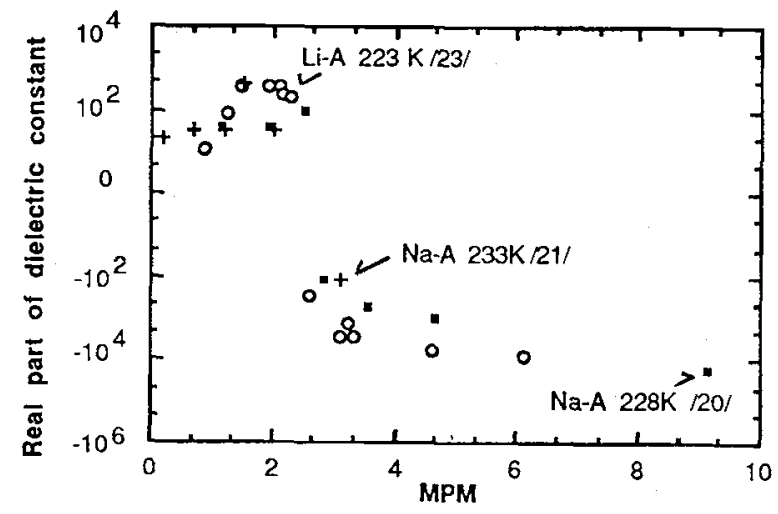

Fig. 2 Real part of the dielectric constant in $\mathrm{Li}$ - and $\mathrm{Na}$--ammonia solutions 


\section{Microscopic inhomogeneity and MNM transition}

In the previous section we showed that the significant local concentration fluctuation might mask the divergence of the dielectric constant in the vicinity of the metal-nonmetal transition in metal ammonia solutions. The concentration fluctuation at long wave-length limit, $S_{c c}(0)$, in a binary system is given by

$$
S_{c c}(0)=\left(1-X_{1}\right)\left(d \ln a_{1} / d X_{1}\right)^{-1}
$$

where $a_{1}$ and $X_{1}$ are the activity and the mole fraction of the component 1 . We can determine the values of $S_{\mathrm{cc}}(0)$ from thermodynamic measurements of activities of the solvent in MAS. The vapor pressures of the solvent in $\mathrm{Li}-, \mathrm{Na}-, \mathrm{K}-, \mathrm{Rb}$ - and $\mathrm{Cs}-\mathrm{NH}_{3}$ have been measured by Marshall/26/. The activities of methylamine in $\mathrm{Li}-\mathrm{CH}_{3} \mathrm{NH}_{2}$ have also been determined from vapor pressure measurements/27/. The experimental results of $\mathrm{S}_{\mathrm{cc}}(0)$ for $\mathrm{Li}-\mathrm{NH}_{3}, \mathrm{Na}-\mathrm{NH}_{3}$ and $\mathrm{Li}-\mathrm{CH}_{3} \mathrm{NH}_{2}$ are shown in Fig. 3. The curves for $\mathrm{Li}-\mathrm{NH}_{3}$ and $\mathrm{Na}-\mathrm{NH}_{3}$ show maxima around $4 \mathrm{MPM}$, while the peak for $\mathrm{Li}-\mathrm{CH}_{3} \mathrm{NH}_{2}$ is located around $7 \mathrm{MPM}$. The results for $\mathrm{Li}$ - and $\mathrm{Na}-\mathrm{NH}_{3}$ are in reasonable agreement with those from the EMF data/28/.

In metal-ammonia solutions, as is well known, these large concentration fluctuations are related to the liquid-liquid phase separation. Critical concentration and temperature for $\mathrm{Li}-\mathrm{NH}_{3}$ are 4.35 MPM and $209.7 \mathrm{~K}$, and those for $\mathrm{Na}-\mathrm{NH}_{3}$ are 4.12 MPM and $231.5 \mathrm{~K} / 29 \%$. Since the critical concentrations coincide with the metal-nonmetal transition points in these solutions, the correlation of the microscopic inhomogeneity and the electronic transport mechanism have been argued by several authors. Cohen and Jortner have proposed a percolation approach to the electronic transport properties $/ 30,31 \%$. According to them, the concentration fluctuations are assumed to be bimodal, varying locally about either of two well-defined compositions, $\mathrm{M}_{\mathrm{o}}$ and $\mathrm{M}_{1}$; in $\mathrm{Li}-\mathrm{NH}_{3}$ and $\mathrm{Na}-\mathrm{NH}_{3}$ $\mathrm{M}_{\mathrm{o}}=9 \mathrm{MPM}$ and $\mathrm{M}_{1}=2.3 \mathrm{MPM} / 30 /$. Critical fluctuations, however, have been demonstrated to be unimodal by Chieux and coworkers from small angle neutron scattering(SANS) experiments for Li$\mathrm{ND}_{3} / 32 /$ and $\mathrm{Na}-\mathrm{ND}_{3} / 33 /$ in the vicinity of the critical point. It has been shown that the concentration fluctuation at the long wavelength limit, $\mathrm{S}_{\mathrm{cc}}(0)$, determined from SANS experiments for $\mathrm{Li}-\mathrm{ND}_{3} / 32 /$ is in fair agreement with the thermodynamic one/34/. In $\mathrm{Li}-\mathrm{CH}_{3} \mathrm{NH}_{2}$ the peak of thermodynamic $\mathrm{S}_{\mathrm{cc}}(0)$ is located around $7 \mathrm{MPM}$, while the MNM transition occurs above $15 \mathrm{MPM} / 10 /$. In this system, therefore, no correlation is found between the thermodynamic instability and the metalnonmetal transition. The present author has concluded that no liquid-liquid demixing region exists in the phase diagram of $\mathrm{Li}-\mathrm{CH}_{3} \mathrm{NH}_{2} / 35$ /

Here, we will made a comparison of some experimental results for these two kinds of solutions, which would reflect the difference in local inhomogeneity of the solutions. Fig. 4 shows Warren's enhancement factors $/ 36 /$ as a function of bulk electrical conductivity for three MAS's, $\mathrm{Li}-\mathrm{NH}_{3}, \mathrm{Na}-$ $\mathrm{NH}_{3}$ and $\mathrm{Li}-\mathrm{CH}_{3} \mathrm{NH}_{2} / 9 /$. The enhancement factor $\mathrm{H}$ is defined as

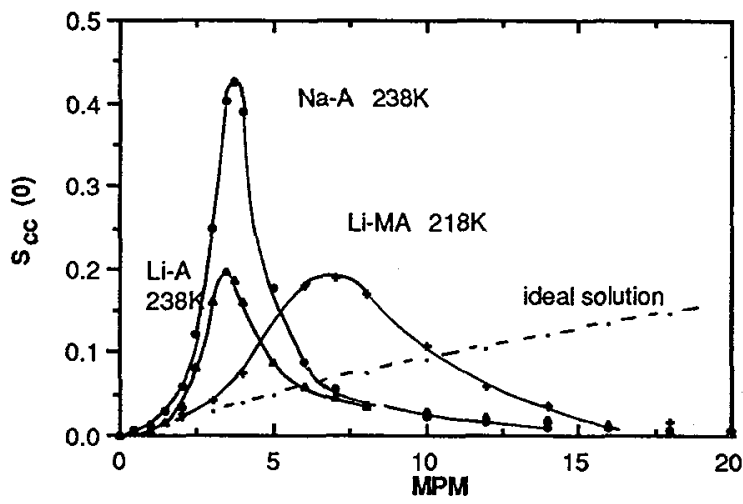

Fig. 3 Concentration fluctuation at low wave length limit in MAS 


$$
\mathrm{H}=\left(1 / \mathrm{T}_{1}\right)_{\mathrm{e}} /\left(1 / \mathrm{T}_{1}\right)_{\mathrm{Korr}}
$$

where $\left(1 / \mathrm{T}_{1}\right)_{\mathrm{e}}$ is the electronic contribution of the observed relaxation rate for the nucleus under study and $\left(1 / \mathrm{T}_{1}\right)_{\text {Korr }}$ is that calculated from the Korringa relation with the knowledge of the Knight shift. This factor is a measure of electron localization in the system. In the metallic state this factor takes a value around unity. It has been found that the enhancement occurs at much lower metal concentration in $\mathrm{Na}-\mathrm{NH}_{3}$ in comparison with that of $\mathrm{Li}-\mathrm{CH}_{3} \mathrm{NH}_{2}$. This indicates that the local metallization seen by NMR takes place at the composition where the bulk conductivity value is still nonmetallic. We may suppose that this local metallization is closely related to the microscopic inhomogeneity in the transition region of metal-ammonia solutions.

As an effect of concentration fluctuations on electrical properties of MAS, Damay and Chieux have reported/40/ that thermoelectric power of $\mathrm{Na}-\mathrm{NH}_{3}$ show non-linear temperature dependence in the vicinity of the critical point. Here we plot in Fig. 5 our results on the relation of the electrical conductivity and thermoelectric power for $\mathrm{Li}-\mathrm{NH}_{3} / 37 /, \mathrm{Na}-\mathrm{NH}_{3} / 38 / \mathrm{Li}_{-} \mathrm{CH}_{3} \mathrm{NH}_{2} / 10 /$. The linear relation often found in liquid semiconductors/39/ is also hold for $\mathrm{Li}-\mathrm{CH}_{3} \mathrm{NH}_{2}$, while deviation from the linear relation is large in $\mathrm{Na}^{-\mathrm{NH}_{3}}$. It seems that this deviation is also related to local inhomogeneity or concentration fluctuations in the solutions. We could not, however, detect any anomalous behavior of the thermoelectric power itself in $\mathrm{Na}-\mathrm{NH}_{3} / 38 /$ as reported by Damay $/ 40 \%$.

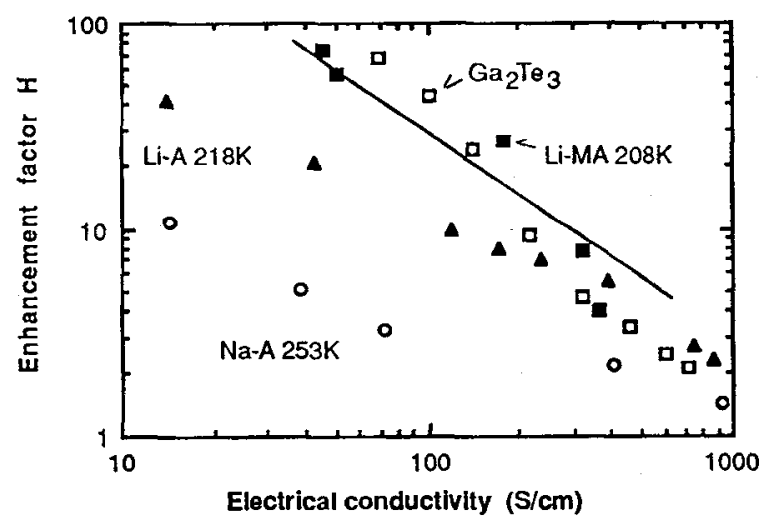

Fig. 4 Warren's enhancement factor $\mathrm{H}$ in some MAS and molten gallium telluride

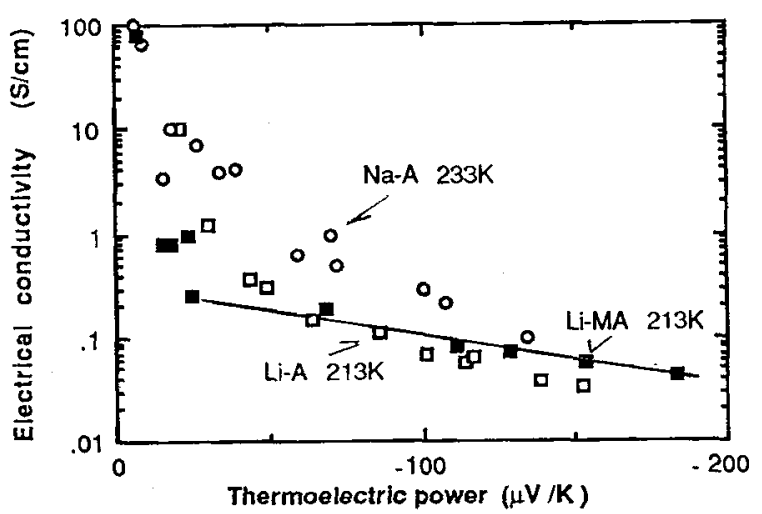

Fig. 5 Relation between electrical conductivity and thermoelectric power 


\section{NMR relaxation measurements and skin effect}

Compared to extensive works on the NMR shifts for MAS, reports on NMR relaxation times in the intermediate and concentrated solution ranges are rather limited. This is mainly due to the experimental difficulties associated with highly conducting samples. The applied electromagnetic wave of radio frequency cannot penetrate into highly conducting samples due to the so-called skin effect. Therefore, NMR measurements for metals are usually made for fine particles, which have radii smaller than the skin depth $\delta$. For MAS this technique cannot be employed, because of the chemically unstable nature of these solutions, when they are dispersed as fine particles in insulating material such as quartz powder. Here we will examine problems arising in samples contained in a cylindrical sample tube.

In highly conducting samples, the applied pulsed magnetic field $\mathrm{H}_{1}$ is reduced exponentially with distance $x$ from the surface of the samples, as given by $H_{1}(x)=H_{1} \exp (-x / \delta)$. Then, the rotation angle of the magnetization after a $\pi$ pulse is varying with distance as $\theta(x)=\pi \exp (-x / \delta)$. Here $\delta$ is the skin depth given by

$$
\delta=(1 / \pi v \sigma \mu)^{1 / 2}
$$

where $\sigma$ and $\mu$ is the electrical conductivity and magnetic susceptibility of the sample liquid and $v$ is the frequency of the applied $\mathrm{H}_{1}$ field. An appropriate value of $\mathrm{H}_{1}$ as the $\pi\left(180^{\circ}\right)$ pulse for the magnetization at the surface is no longer sufficient for the magnetization interior of the sample. For such a case, we may use the $\pi-\tau-(-\pi / 2)$ pulse sequence instead of the usual $\pi-\tau-\pi / 2$ sequence and improve the accuracy of observed values of the spin-lattice relaxation time $T_{1}$ However, the effect of diffusion of spins in and out of the skin depth region cannot be avoided for metallic samples. This effect is well known in ESR measurements of conduction electrons in metals and the theoretical interpretation has been established by Dyson/41/. The skin effect in NMR measurements, however, is appreciable only in samples which have relatively long $T_{1}$ values. In the following we will examine this skin effect in NMR $\mathrm{T}_{1}$ measurements more quantitatively/42/.

In Fig 6, we plot values of $\delta$ at $100 \mathrm{MHz}$ for $\mathrm{Li}-\mathrm{NH}_{3}$ and $\mathrm{Li}-\mathrm{CH}_{3} \mathrm{NH}_{2}$. These values of $\delta$ should be divided by 10 for frequencies of $10 \mathrm{GHz}$, corresponding to the $\mathrm{X}$-band. For liquid samples, a part of the excited nuclear spins may diffuse out of the skin depth region during $\mathrm{T}_{1}$ measurements. The diffusion length $\mathrm{L}$ for a nuclei with $\mathrm{T}_{1}=10 \mathrm{~s}$ and the diffusion coefficient $\mathrm{D}=$ $5 \times 10^{-5} \mathrm{~cm}^{2} / \mathrm{s}$, is estimated from the relation, $\mathrm{L} \cong\left(\mathrm{D} / \mathrm{T}_{1}\right)^{1 / 2}$, to be $\mathrm{L} \cong 200 \mu \mathrm{m}$. This is of comparable order of magnitude with the skin depth of concentrated metal-ammonia solutions at $100 \mathrm{MHz}$.

After an exact $\pi$ pulse for the surface magnetization, the initial distribution of the z-component of the magnetization, $M_{z}(x, 0)$, over the equilibrium value $M_{0}$, is given by

$$
M_{z}(x, 0)-M_{o}=M_{0}\left\{\cos \left(\pi e^{-x / \delta}\right)-1\right\} \cong-2 M_{o} \exp \left(-x^{2} / \delta^{2}\right) .
$$

If we take the approximate form given above, we can solve the Bloch equation for diffusing nuclei/42/. The magnetization over the equilibrium value in the skin depth region can be observed as a function of $t$, which is given by

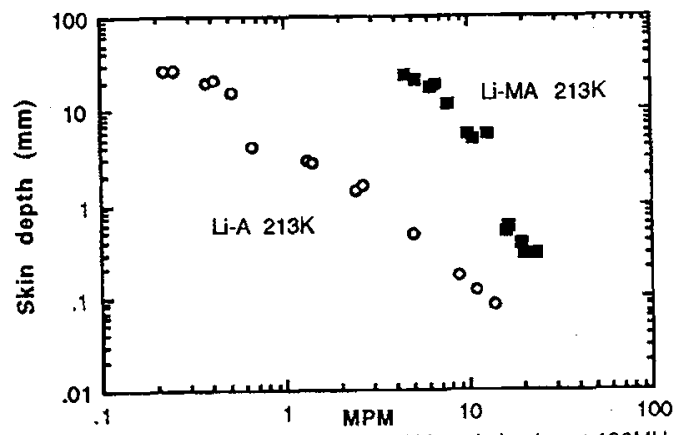

Fig. 6 Skin depth for Li-ammonia and Li-methylamine at $100 \mathrm{MHz}$

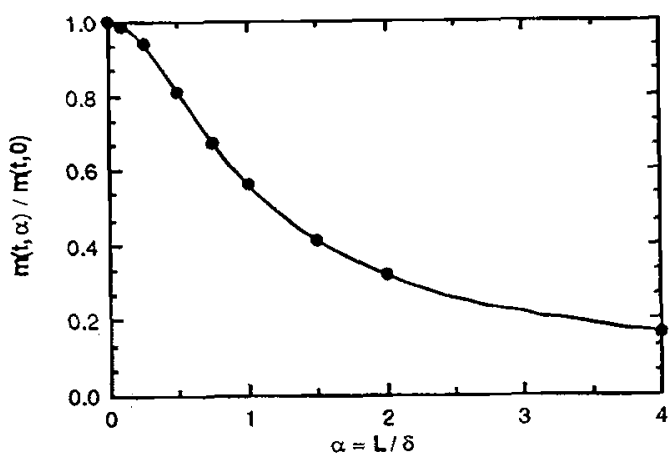

Fig. 7 Reduction of obserbvable magnetization due to the skin effect 


$$
m(t, \alpha)=\int_{0}^{\delta}\left\{M_{z}(x, t)-M_{0}\right\} d x=-\sqrt{\pi} \delta M_{0} \Phi\left(1 / \sqrt{1+4 \alpha^{2}}\right) \exp \left(-t / T_{1}\right)
$$

where $\alpha=L / \delta$ and $\Phi(y)$ is the error function defined by $\Phi(y)=(2 / \sqrt{\pi}) \int_{0}^{y} \exp \left(-y^{2}\right) d y^{\prime}$. The skin effect on the observed magnetization is therefore expressed by the factor of the error function. In Fig. 7, we plot the ratio $m(t, \alpha) / m(t, \alpha=0)$ as a function of $\alpha$., which is a measure of the extent of the skin effect. The case of $\alpha=0$ corresponds to the absence of the skin effect, i.e., a large enough skin depth and/or negligiblly small diffusion length of the spins during $T_{1}$ or very short $T_{1}$. As seen in Figure 7, the effect of skin depth on the observed $T_{1}$ is relatively small until $\alpha=0.2$. At $\alpha=2$, however, the contribution of the spin diffusion to the observed relaxation time is comparable to that of the normal relaxation process.

At the frequencies used $\left(90 \mathrm{MHz}\right.$ for $\left.{ }^{1} \mathrm{H}\right)$, the typical values of $\mathrm{L}$ in $\mu \mathrm{m}$ are 170 for ${ }^{1} \mathrm{H}, 200$ for ${ }^{7} \mathrm{Li}, 7$ for ${ }^{14} \mathrm{~N}$ and 20 for ${ }^{23} \mathrm{Na}$. At $8 \mathrm{MPM}$ the calculated values of $\alpha$ are $1\left({ }^{1} \mathrm{H}\right), 0.7\left({ }^{7} \mathrm{Li}\right)$, $0.05\left({ }^{14} \mathrm{~N}\right)$ and $0.2\left({ }^{23} \mathrm{Na}\right)$, respectively. We can conclude that for ${ }^{14} \mathrm{~N}$ and ${ }^{23} \mathrm{Na}$ the skin effect is negligible over the entire concentration range, while for ${ }^{1} \mathrm{H}$ and ${ }^{7} \mathrm{Li}$ this effect cannot be neglected, when samples have the electrical conductivity larger than $1000 \mathrm{~S} / \mathrm{cm}$. In fact, the observed relaxation rates/45/ increase around $8 \mathrm{MPM}$ for ${ }^{1} \mathrm{H}$ and ${ }^{7} \mathrm{Li}$ as shown in Fig. 8, while such apparent increase of the relaxation rates were not found for ${ }^{14} \mathrm{~N}$ and ${ }^{23} \mathrm{Na}$, in accordance with the estimation given above. Foreseeing this apparent increase of the relaxation rates, the data of $1 / \mathrm{T}_{1}$ for ${ }^{1} \mathrm{H}$ and ${ }^{7} \mathrm{Li}$ in ammonia above $8 \mathrm{MPM}$ were not used in our analysis/9/. In $\mathrm{Li}-\mathrm{CH}_{3} \mathrm{NH}_{2}$ on the other hand, the skin effect were negligible for all the nuclei studied, as the maximum conductivity of this system is of the order of $400 \mathrm{~S} / \mathrm{cm}$. As reported elsewhere $/ 9,11,35 /$, the nuclear spin relaxation data for MAS are interpreted in terms of hyperfine interaction with the excess electrons which become more and more mobile with increase of metal concentration. In the metallic region, the relaxation can be described by the Korringa formula as in usual liquid metals as already shown in Fig. 4.

In recent ESR measurements on MAS, X-band frequencies are usually used. Then, the skin effects are inevitable for conducting samples. At X-band frequencies dilute MAS's are characterized by a narrow symmetrical ESR line, while concentrated MAS's show an asymmetric line shape characteristic of metals. This asymmetric lineshape is due to the diffusion of the excited electron spins out of the skin depth of the sample solutions. For usual sample configurations the lineshape may be analyzed by Dyson's theory/41/ as thick metals/43/, in which the thickness of samples is much larger than the skin depth $\delta$. Recently we have started ESR measurements at the same frequencies as for NMR measurements, i.e., around $200 \mathrm{MHz}$. Some of the preliminary results will be given in the next section.

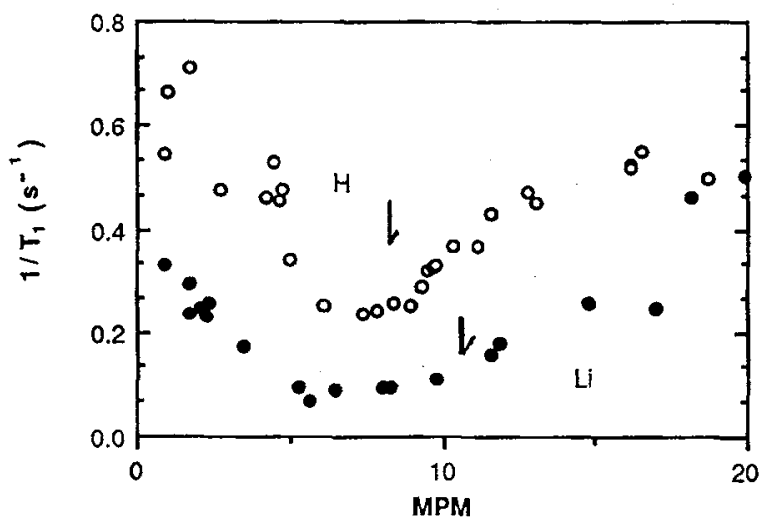

Fig. 8 Enhancement of the relaxation rate due to the skin effect 


\section{Low-field ESR measurements}

Early experiments of ESR on metal-ammonia solutions were made at relatively low magnetic field, 7 to $300 \mathrm{MHz} / 44 /$. The measurements were mostly concerned with establishing the nature of the electronic species in the dilute solution range. The linewidths, line shape and the g-values were measured as a functions of metal concentration and temperature. Later measurements were usually made at higher frequencies such as at X-band or around $10 \mathrm{GHz}$. The role of ESR investigation, as well as that of NMR, in understanding the electronic structure of metal-ammonia(amine) solutions has been reviewed by Edwards/7/at Colloque Weyl VI. The pulsed ESR measurements at X-band frequencies on $\mathrm{Li}-\mathrm{CH}_{3} \mathrm{NH}_{2}$ have also been reported at Colloque Weyl VI/46/. It should be noted that the first spin-echo measurements were made on $\mathrm{Na}-\mathrm{NH}_{3}$ by Blume/47/ at $17.4 \mathrm{MHz}$ as early as in 1958.

Thus, we have started our low-field ESR experiments with both the CW and the pulse technique with collaboration of Shimokawa and others/48/. Our CW measurements by a home made spectrometer were performed at $200 \mathrm{MHz}$ with a stabilized electromagnet for NMR in the temperature range from 170 to $250 \mathrm{~K}$. Modulation frequencies of 2 to $6 \mathrm{KHz}$ were used. Sample solutions were contained in Pyrex glass tubes of $4 \mathrm{~mm}$ i.d. In the following we present some of the preliminary results obtained for $\mathrm{Li}-\mathrm{CH}_{3} \mathrm{NH}_{2}$. As examples, the spectra for $\mathrm{Li}-\mathrm{CH}_{3} \mathrm{NH}_{2}$ with 11.7 MPM (nonmetallic) and 23.2 MPM (metallic) are shown in Fig. 9, and compared with the corresponding results obtained at the X-band/49/. The present result on the metallic sample is relatively symmetric, indicating a reduction of skin effect. Fig. 10 shows the change of the integrated intensity of the absorption spectra per dissolved metal in the nonmetallic region. The observed intensity increases with temperature and shows a trend to decrease with increase of metal concentration. The temperature and composition dependence of the apparent spin-spin relaxation time, $\mathrm{T}_{2}{ }^{*}$, for $\mathrm{Li}-\mathrm{CH}_{3} \mathrm{NH}_{2}$ is shown in Fig. 11. Although the present results are about a half of the reported $\mathrm{T}_{2}$ by the spin-echo method $/ 46 /$, the qualitative features are in good agreement. The relaxation time, $\mathrm{T}_{2}{ }^{*}$ increases with metal concentration and also with temperature in the composition range studied, where the solutions are nonmetallic. In dilute solution of MAS, the dominant contribution to the electron spin-lattice relaxation rate is given by the modulation of the hyperfine contact interaction with nitrogen nuclei/46,49/. In the extreme narrowing region, the relaxation rate is proportional to the correlation time of the interaction $\tau_{\mathrm{c}}$ and the electron spin density at the nitrogen nucleus, $|\Psi(0)|_{\mathrm{N}}^{2}$. The observed decrease of the relaxation rate with temperature is mainly attributed to the decrease of $\tau_{c}$ with increase of temperature and metal concentration. We have also constructed a pulsed ESR spectrometer operating at around $200 \mathrm{MHz}$. Experiments are still under way, and we could, for the moment, observe ${ }^{1} \mathrm{H}$ NMR spectra with the home made spectrometer at $200 \mathrm{MHz}$. We are planning to measure the electron spin paramagnetism with the method proposed by Schumacher and Slichter $/ 12 /$, in which the integral intensity of absorption curves for electrons and the nuclei under study from the same sample and measuring circuit.

$10 \mathrm{GHz}$

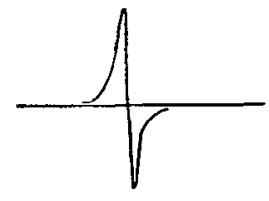

11.7 MPM (0.95 G)

$200 \mathrm{MHz}$

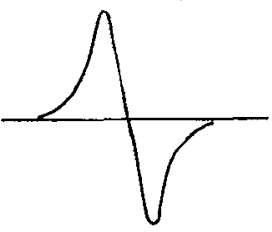

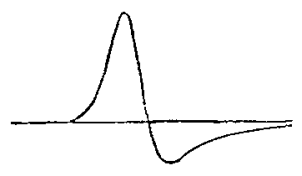

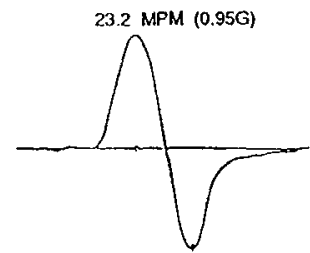

$260 \mathrm{~K}$

$233 \mathrm{~K}$

Fig.9 ESR spectra of Li-methylamine at $10 \mathrm{GHz} / 49 /$ and $200 \mathrm{MHz} / 48$ / 


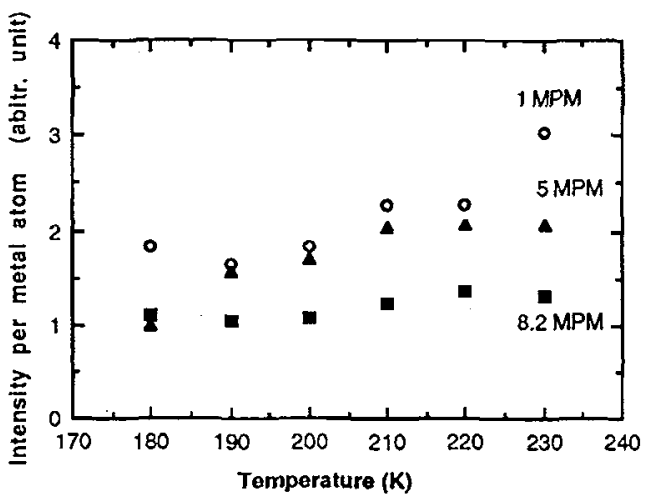

Fig. 10 Intensity of ESR spoctra per dissolved metal in Li-MA

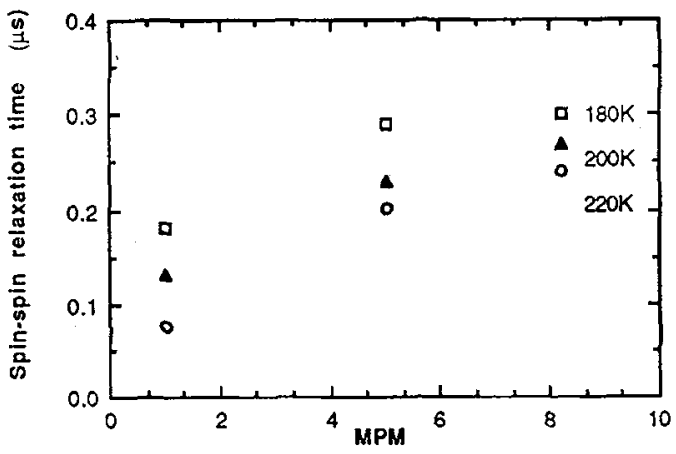

Fig. 11 Apparent electron spin-spin relaxation time in Li-MA

\section{Summary and Conclusion}

In this review I have summarized experimental findings on the physical properties of MAS, observed mainly by the magnetic resonance methods. Excess electrons in solutions are described as free non-interacting spins at the two extremities, i.e., in infinitely dilute solutions and nearly free electron metals. Most interesting phenomena, however, come from the intermediate region, where solutions exhibit metal-nonmetal transitions. Instability of the solutions or tendency of phase separation and spin-pairing phenomena strongly affect the characteristics of MAS. Analogies of MAS are often found in metal-molten salt solutions and expanded metals. We may note that twodimensional MAS have been realized in graphite intercalation compounds/51/.

Further studies on physical properties of MAS should be focused on the low temperature phases of MAS, including amorphous solids and crystalline compounds. Another important points are spinpairing phenomena, which may be related to anomalous electric conductance often reported as a sort of superconductivity. One may cite here recent papers which report appearance of superconductivity in $\mathrm{K}-\mathrm{C}_{60} / 52 /$ and in $\mathrm{Rb}-\mathrm{C}_{60} / 53 /$. This is also a combination of alkali metal and a molecular entity. I think that metal-ammonia(amine) solutions are still intriguing for both chemists and physicists.

\section{References}

11. C.A.Hutchison and R.C.Pastor, J. Chem. Phys., 21 (1953) 1959.

12\%. a) U.Schindewolf, Z.Phys. Chem. NF, 112 (1978) 153; (b) W. Essig and

U.Schindewolf, Ber. Bunsengesell., 82 (1978) 1249.

13/. J.P.Lelieur and P.Rigny, J. Chem. Phys., 59 (1973) 1142.

14/. R.L.Harris and J.J.Lagowski, J. Phys.Chem., 85 (1981) 8566.

15\%. A.Depriester, J.Fackeure and J.P.Lelieur, J.Phys. Chem., 85 (1981) 272.

16/. J.L.Dye, C.W.Andrews and J.M.Ceraso, J. Phys.Chem.,79 (1975)3076.

77\%. P.P.Edwards, J. Phys. Chem., 88 (1984) 3772.

/8/. J.L.Dye, J. Phys. Chem., 84 (1980) 1084.

19\%. Y.Nakamura, M.Niibe and M.Shimoji, J. Phys. Chem., 88 (1984)3755.

/10/. T.Toma, Y.Nakamura and M.Shimoji, Phil. Mag., 33 (1976) 181.

111/. M.Niibe and Y.Nakamura, J. Phys. Chem., 88 (1984) 5608.

/12/. R.T.Schumacher and C.P.Slichter, Phys. Rev., 101 (1956) 58.

/13/. I.M.Dmitrenko and I.S.Shchetkin, Zh. E.T.Fiz., Pisma, 18 (1973) 497.

/14/. I.M.Dmitrenko and I.O.Kulik, Phys. Stat. Sol., (b) 64 (1974) K13.

/15/. P.Arendt, Ber. Bunsengesell., 91 (1987) 1363. 
/16/. P.P.Edwards and M.J. Sienko, Phys. Rev. B, 17(1978) 2575.

/17/. K.F.Herzfeld, Phys. Rev., 29 (1927) 701.

/18/. P.P.Edwards and M.J.Sienko, Acc. Chem. Res., 15 (1982), 87.

/19/. J.C.Thompson, J. Sol. State Chem., 54 (1984) 308.

120\%. D.W.Mahaffey and D.A.Jerde, Rev.Mod.Phys.,40 (1968) 710.

121/. K.G.Breitschwerdt and H.Radscheit, "Electrons in Fluids", Ed.J.Jortner and N.R.Kestner, Springer Verlag, Heiderberg, (1973) p.315.

/22/. K.G.Breitschwerdt and H.Radsheit, Phys. Lett. 50A (1975) 423.

123/. P.Damay, F.Leclercq and J.P.Lelieur, Phil. Mag.B, 57 (1988) 75.

124/. F.Leclercq and P.Damay, Phil. Mag.B, 57 (1988) 61.

125/. H.F.Hess, K.DeConde, T.F.Rosenbaum and G.A.Thomas, Phys. Rev. B, 25 (1982) 5578.

126/. P.P.Marshall, J. Chem. Eng. Data, 7 (1962) 399.

127/. Y.Nakamura, Y.Horie and M.Shimoji, J. Chem.Soc., Faraday Trans. I, 70 (1974) 1376.

128\%. K.Ichikawa and J.C.Thompson, J. Chem. Phys., 59 (1973) 1680.

/29/. J.C.Thompson,"Electrons in Liquid Ammonia", Oxford Univ. Press (Clarendon), Oxford (1976).

130/. (a) J.Jortner and M.H.Cohen, J. Chem. Phys., 58 (1973) 5170;

(b) M.H.Cohen and J.Jortner, J.Phys. Chem., 79 (1975) 2900.

131/. J.Jortner and M.H.Cohen, Phys. Rev. B, 13 (1976) 1548.

132/. P.Chieux, Phys. Lett., 48A (1974) 493.

133/. P.Damay, F.Leclercq and P.Chieux, J. Phys. Chem., 88 (1984) 3734.

134/. P.Chieux and P.Damay, Chem. Phys. Lett., 58 (1978) 619.

135/. Y.Nakamura and T.Kikuchi, J. Phys. Chem., 91 (1987) 3704.

136/. W.W.Warren Jr., Phys. Rev. B, 3 (1971) 3708.

/37/. M.Hirasawa, Y.Nakamura and Shimoji, Ber. Bunsengesell., 82 (1978) 815.

/38/. T.Kadowaki, T.Okamoto and Y.Nakamura, unpublished work

139\%. Y.Ninomiya, Y.Nakamura and M.Shimoji, J.Non-Cryst. solids, 17 (1975) 231.

140\%. P.Damay and P.Chieux, J. Phys. Chem., 84 (1980) 1203.

141/. M.Niibe, Thesis, Hokkaido University (1983).

/42/. F.J.Dyson, Phys. Rev., 98 (1955) 349.

143/. P.Damay, F.Leclercq and P.Devolder, J. Phys. Chem., 88 (1984) 3760.

144/. R.S.Alger, "Electron Paramagnetic Resonance", Intersci. New York (1968) p. 290.

145/. T.Toma, M.Hirasawa and Y.Nakamura, unpublished work.

146/. C.J.Page, G.L.Millhauser, P.P.Edwards, J.H.Freed and M.J.Sienko, J. Phys. Chem., 88 (1984) 3785.

/47/. R.J.Blume, Phys. Rev., 109 (1958) 1867.

/48/. S.Shimokawa, E.Yamada, H.Matsui, T.Haraguchi and Y.Nakamura, to be published.

/49/. J.R.Buntaine, M.J.Sienko and P.P.Edwards, J. Phys. Chem., 84 (1980) 1230.

/50/. D.E.O'Reilly, J. Chem. Phys., 35 (1961) 1856.

151\%. S.A.Solin and Y.Y.Huang, Synth. Metals, 23 (1988) 223.

152/. A.F.Hebard,M.J.Rosseinsky,R.C.Haddon,D.W.Murphy,S.H.Glarum,T.T.M.Parstra, A.P.Ramirez and A.R.Kortan, Nature, 350 (1991) 600.

153/. M.J.Rosseinsky,A.P.Ramirez,S.H.Glarum.D.H.Murphy,R.C.Haddon,A.F.Hebard. T.T.Palstra,A.R.Kortan,S.M.Zahurak,and A.V.Makhija, Phys. Rev. Lett., 66 (1991) 2830 . 